\title{
Wind ventilation in the built environment
}

\author{
E. Ö. Aktuğlu Aktan \\ Yildiz Technical University, Istanbul, Turkey
}

\begin{abstract}
Wind is the perceptible natural movement of the air, especially in the form of a current of air blowing from a particular direction. Wind is caused by differences in atmospheric pressure. Wind is the kinetic energy of air in motion. It is a renewable energy which comes from natural resources which are naturally replenished. Wind power is conversion of wind energy into a useful form of energy.

Wind ventilation is a kind of passive ventilation, using the force of the wind (or local air pressure differences) to pull air through the building. Wind ventilation is the easiest, most common, and often least expensive form of passive cooling and ventilation. The use of natural ventilation is definitely an advantage with the raising concerns regarding the cost and environmental impact of energy use. The natural ventilation provides ventilation (outdoor air) to ensure safe healthy and comfortable conditions for building occupants and for people on the street without the use of fans. It also provides free cooling without the use of mechanical systems, when the orientation and lay-out of the built-up area useful direction.

For this paper, related literature, articles and books are researched. There are a lot of cases and different approaches in these writings. It is eliminated by the subject of wind ventilation in the built environment. The purpose of this paper is to explain the importance of using wind energy as passive and natural ventilation in the built environment. It is essential to give some guidelines how the wind energy is used for a sustainable lifestyle between the buildings and in the city. Our goal is to reduce the greenhouse gas emissions for the sustainable future. Keywords: wind ventilation, passive cooling effect, thermal comfort, sustainable cities.
\end{abstract}




\section{Introduction}

There is a lengthy history of idealised urban plans that link the physical form of the city to desirable social, religious, cultural or environmental outcomes. The newest urban ideal is the sustainable settlement. It is derived from the concept of sustainable development, which has been broadly defined as that which meets the needs of the present generation while ensuring sufficient resources for future generations.

The phenomenon of city-induced environmental change has been known for many centuries. The ancient Indian architectural manual "Silpa Sastra" (translated by Acharya, 1979) laid out rules for the siting of villages, towns and forts based on prevailing wind directions and solar orientation [1].

There are clear links between the climate of a settlement and its potential sustainability. Its opportunities for gathering energy, its need for energy conservation and its ability to dispose of airborne wastes are largely controlled by the climate it experiences. Moreover, urban design decisions will create microclimates that either accentuate or moderate the properties of the background climate. Thus, there is a clear role for an applied urban climatology in the planning of sustainable settlements [2, p. 69].

A major goal of sustainable planning is reduce domestic energy demand so design guidelines that focuses on solar access and ventilation for energy gain and loss, respectively, are more likely to be incorporated into sustainable practice $[2$, p. 74,3$]$

The world's temperature will be higher than now. Sun and wind are very essential. Wind can be cooler the streets or open places in hot summers. We have to design cities with using natural data as sun and wind. There are a lot of researches about natural ventilation. There are a lot of researches about natural ventilation. This is a part of climate sensitive design. The aim of this study is arrange these researches and give some major points about natural ventilation. Urban geometry effects on the microclimate. In order to need of reduction in energy usage, develop some guidelines for urban design, which can be used to mitigate heat stress during extreme weather situations. Satisfaction with the thermal environment is important for its own sake and because it influences productivity and health.

\section{Climate sensitive designs}

Buildings of the future must be designed and constructed to reduce energy demand. From a thermal point of view, technologies to minimize heating needs already exist. But in order to reduce future cooling requirements, more positive action will be required. This applies both in commercial buildings, where cooling demand is already significant, and in the domestic sector, where air conditioning is gaining a foothold [4].

The goal of climate-sensitive urban design is to achieve human comfort for a majority of urban dwellers. Although the knowledge of thermal comfort in the indoors is well advanced, the study of urban comfort lags behind due to the 
complexities of outdoor radiation balance and the wind regime $[1, \mathrm{p} .4]$. The study of urban thermal comfort in the built environment is very essential.

During the last decade, relatively few studies on thermal comfort for outdoor environments have been done compared to indoor environments, although the importance of the former is increasingly recognized with changing climate and increase of heat stress in cities. The difficulty in assessing thermal outdoor conditions is that the climatic variables are much more diverse than in indoor settings [5, p. 43].

The outdoor comfort indices based on energy balance of the human body should also use meteorological variables (air temperature, humidity, radiation, and wind speed) and human factors (clothing and metabolism) [5, p. 44].

Human biological cycles are highly interfered by climate and weather. The way one works, gets exhausted, and recovers is affected by meteorological variables, such as air temperature, relative humidity, solar radiation and wind speed [6].

\section{Human comfort}

Comfort is best defined as the absence of discomfort. People feel uncomfortable when they are too hot or too cold, or when the air is odorous and stale. Positive comfort conditions are those that do not distract by causing unpleasant sensations of temperature, drafts, humidity, or other aspects of the environment. Ideally, in a properly conditioned space, people should not be aware of equipment noise, heat, or air motion.

The feeling of comfort - or, more accurately, discomfort - is based on a network of sense organs: the eyes, ears, nose, tactile sensors, heat sensors, and brain [7].

\subsection{Thermal comfort}

Temperature is the most significant component to the experience of comfort in a space. Our bodies perform within an internal temperature range much narrower than external temperatures. In the process our bodies' metabolism generates heat, which must dissipate into the surrounding air or surfaces $[8, \mathrm{p} .1]$.

When external temperatures are high, this process becomes more difficult and we may overheat or feel warm. When external temperatures are low, the rate of heat loss becomes more rapid, and we may feel uncomfortably cold [8, p. 2].

Thermal comfort is that state of mind that is satisfied with the thermal environment; it is thus the condition of minimal stimulation of the skin's heat sensors and of the heat-sensing portion of the brain [7].

The environmental conditions conducive to thermal comfort are not absolute, but rather vary with the individual's metabolism, the nature of the activity engaged in, and the body's ability to adjust to a wider or narrower range of ambience. 
For comfort and efficiency, the human body requires a fairly narrow range of environmental conditions compared with the full scope of those found in nature. The factors that affect humans pleasantly or adversely include:

1. Temperature of the surrounding air

2. Radiant temperatures of the surrounding surfaces

3. Humidity of the air

4. Air motion

5. Odors

6. Dust

7. Aesthetics

8. Acoustics

9. Lighting

Of these, the first four relate to thermal interactions between people and their immediate environment $[7$, p. 5].

\subsubsection{Air motion}

Air motion (wind) is nothing more than the movement of air molecules from one place to the next. The direction and speed of the wind represents the balance between three basic forces acting on it: the pressure gradient, the coriolis force, and surface friction [9].

The "undisturbed" wind is called the "gradient wind" and its velocity is the "gradient velocity". Usually, the "gradient wind" flows at a height of several hundred meters above ground. However, near the ground the wind experiences friction. Its speed is retarded drastically and its turbulence (i.e. speed variation) increases even within a short distance. Both parameters of wind (speed and turbulence) are affected by the topography as well as by the urban form. Elements that retard wind flow in urban areas are called the urban "roughness elements".

The urban roughness elements are mainly buildings that are rigid sharpangled bodies distributed along streets. This causes the wind speeds to be retarded, but at the same time the turbulence of the flow is greatly enhanced. The specific design details of the buildings and the streets, the height of the buildings relative to one another, and the orientation of the buildings with respect to the wind, greatly affect the actual wind flow within the urban canopy layer.

The main design elements that modify wind flows within the urban canopy layer are:

- The overall density of the urban area;

- Size and height of individual buildings;

- Existence of high-rise buildings;

- Street orientation;

- Availability, size and distribution of open areas and green belts. $[2$, p. 116, 10].

The primary task of designing for wind movement should begin at city level, particularly in its street layout pattern. Streets should be so aligned to reap the maximum benefit from macro-level wind directions [1, p. 118]. 


\subsubsection{Velocity of air}

Air velocity plays a role in the perception of thermal comfort. In hot weather, as the body tries to cool itself, the flow of air across the body will assist evaporative cooling from sweating. When air has a high relative humidity, the air next to the sweating body may become saturated with moisture, but by moving the air next to the body away and bringing in fresh, lower-humidity air, the evaporation of sweat can continue. Mechanisms of convection can further move the heat generated by metabolic processes from the skin and into the surrounding air. All this leads to continued cooling, and the higher the velocity of air, the more effective is the process [8, pp. 2-3].

As helpful as airflow can be in warm and humid conditions, it can be problematic in others. In cool settings, the same processes of evaporative cooling and convection, which play a key part in cooling the warm body, may cool the inhabitants beyond their levels of comfort. Aside from the cooling effect of airflow, the air speed itself can cause discomfort. Generally, airflow slower than 100 feet per minute feels either pleasant or goes unnoticed. Higher than that, and the flow of air can within an enclosed space can provoke distraction (up to $200 \mathrm{fpm}$ ) and annoyance (above $200 \mathrm{fpm}$ ) [8, p. 3, 11].

Air speed is defined as the rate of air movement at a point, without regard to direction. According to ASHRAE Standard 55, it is the average speed of the air to which the body is exposed, with respect to location and time. The temporal average is the same as the air temperature, while the spatial average is based on the assumption that the body is exposed to a uniform air speed. However, some spaces might provide strongly no uniform air velocity fields and consequent skin heat losses that cannot be considered uniform. Therefore, the designer shall decide the proper averaging, especially including air speeds incident on unclothed body parts that have greater cooling effect and potential for local discomfort [12].

\subsubsection{Wind flow in an urban canyon}

The wind flow within an urban canyon is a secondary circulation feature driven by the above-roof dominant flow [13, 14], which is strongly affected by the street orientation and geometry (H: height, L: length, W: width). When the flow over arrays of buildings is approximately normal to street axis, three regimes can take place depending on the aspect ratio $(\mathrm{H} / \mathrm{W})$ and building ratio $(\mathrm{L} / \mathrm{W})$. The transition from one regime to another occurs at critical combinations of $\mathrm{H} / \mathrm{W}$ [15] and L/W [16] (as shown in Fig. 1).

The isolated roughness flow occurs between well-spaced buildings, when the windward and leeward flows do not interact, comparably to a wind movement around an isolated obstacle. As the $\mathrm{H} / \mathrm{W}$ increases, the wakes are disturbed leading to a wake interference regime. With further increase of $\mathrm{H} / \mathrm{W}$, the street canyon becomes isolated from the above circulating air and a stable circulatory vortex is established in-canyon, leading to a skimming flow. The latter regime is the most common in urban contexts and has, therefore, drawn the most attention. The correlation of wind speed between in-canyon and above-roof wind flow is found to be marked for high winds, resulting in a stable vortex circulation. This 

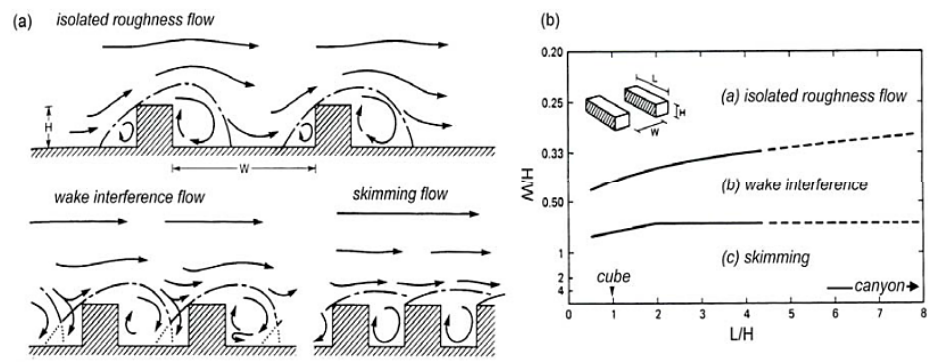

Figure 1: (a) Wind flow regimes [17] and (b) corresponding threshold lines dividing flow into three regimes as function of canyon $(\mathrm{H} / \mathrm{W})$ and building (L/W) geometry [16, 18, p. 31].

correlation is lost for lower wind speeds, leading too much more scattering [13, 14]. A threshold wind speed of $1.5-2.0 \mathrm{~m} / \mathrm{s}$ between both situations was mentioned by McCormick [19], De Paul and Shieh [20] and Nakamura and Oke [13]. Above this threshold, wind speed in the canyon was reported to increase proportionally to free ambient air [20-22]. In the case of light winds, the air canyon flow is not only a mechanically driven circulation but thermal effects due to canyon facets irradiation may play a role $[13,14]$. Explicitly, the temperature cross-section suggests the formation of one circulatory vortex mixing cool air from above the roof into the canyon space and expelling warming air. Moreover, the differential heating of street surfaces can shift the flow from one regime to another [23] and from a one vortex flow to a flow with several contra-rotated vortices [18, p. 32, 23, 24].

In a deep canyon, wind flow at street level relates to the prevailing wind speed above roof level as well as to in-canyon thermal stratification [14]. For perpendicular winds, either one circulatory vortex occurs driven by the ambient air flow, or a double vortex takes place, where the lower vortex is induced from the upper one and is in the opposite direction [14, 25]. The speed of the single vortex results from three specific mechanisms: the ambient air flow above the canyon, the vertical stratification of air inside the canyon, and the mechanism of advection from the buildings ends. When the wind above roof is predominant, the speed within the canyon increases (under a threshold of 2 to $3 \mathrm{~m} / \mathrm{s}$ ). A double vortex is almost always observed, together with temperature stratification. Under these conditions, higher ambient winds contribute to the transmission of more energy from the upper to the lower vortex and hence increase its speed. The wind direction within the canyon depends on the incidence of ambient air in respect to street axis. When the flow at roof level is normal to the canyon axis, an opposite direction prevails at street level [13, 14, 26, 27]. A wind blowing parallel to street axis generates a channeling of the mean wind [13, 14, 28] with possible uplift along the canyon walls due to increased friction near the surfaces [29]. The canyon wind speed is then proportional to free wind speed. When the flow above roof is at some angle of attack on the canyon, a spiral vortex (or cork-screw type) is induced along the canyon [13, 14, 18 p. 32, 28, 30]. This oblique incidence improves the potential of urban ventilation and hence 
promotes the ventilation indoors in comparison to a perpendicular incidence [3133]. The parallel component of the main wind determines the along canyon stretching of the vortex and the transversal component drives the canyon vortex [34].

Furthermore, Chan et al. [35] found that non-uniformly building heights provide better ventilation and tall buildings do not necessarily promote blockage. A wider canyon promotes better mixing of air and canyon geometry should be restricted to threshold value for skimming flow and maximum relative canyon length ratio $\mathrm{L} / \mathrm{H}$ should be kept at five. End canyon effects play an important role on the air flow distribution in canyons. For $\mathrm{L} / \mathrm{W} \approx 20$ finite canyon lengths begin to dominate over the vortex [34].

Intermittent vortices are shed on the building corners, and these vortices are responsible for the mechanism of advection from building corners to mid-block creating a convergence zone in the mid-block region of lowest wind speeds [14, 18, p. 33, 26].

The issue of urban wind is complex and a detailed analysis of the wind flow mechanisms is not possible within the framework of this study. Nevertheless, a number of observations of relevance for the comfort issue are summarized below. These deal mainly with the effects of the incidence of above-roof wind in relation to street axis (perpendicular or parallel) on the near ground wind speed in the canyon. Unlike other meteorological factors, the wind speed (v) shows large differences along the street, namely a strong contrast between street ends and street center [18, p. 125].

\section{i) Perpendicular flow}

Explicitly, near ground wind speed rises with $\mathrm{H} / \mathrm{W}$ until a proportion of 3 , but decreases again for $\mathrm{H} / \mathrm{W}=4$, at which the strong eddy circulation deviating the wind flow from the upper corners through the canyon occurs only at the higher part of the street $(\mathrm{v}>1.2 \mathrm{~m} / \mathrm{s}$ only from $0.5 \mathrm{H})$ and does not reach the street level, leading to lower wind speeds.

The mid-canyon is characterized by a convergent flow from both sides and ranges between 0.3 and $0.1 \mathrm{~m} / \mathrm{s}$ for all canyons regardless of their aspect ratio. The symmetry of these patterns is slightly altered, likely because of thermal effects [14, 18, p. 127].

\section{ii) Parallel flow}

The wind is channeled along the street and flows in the same direction. Because of friction forces near the surfaces, the wind speed decreases progressively along the street with an uplift along the canyon walls until a critical point within the canyon depending on $\mathrm{H} / \mathrm{W}$. The flow is then accelerated again, pushed by the downward flow from roof level. Explicitly, with increasing H/W ratio the canalization and acceleration effects are stronger and the wind speed at the opposite corner experiences higher wind speeds than at the entrance of the canyon. The extent of the acceleration zone also increases, e.g. $20 \%$ for $\mathrm{H} / \mathrm{W}=$ 0.5 vs. $60 \%$ for $\mathrm{H} / \mathrm{W}=2[18, \mathrm{p} .127]$. 


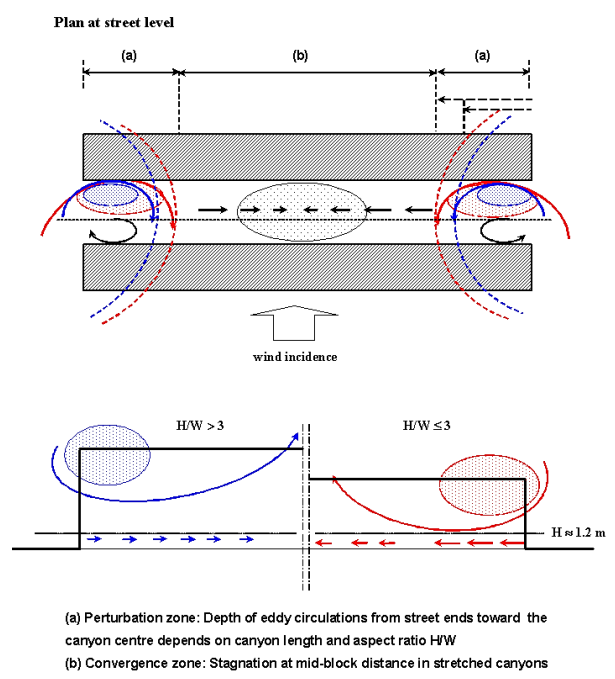

Figure 2: Zones with different ventilation potential and depending on canyon dimensions according to simulation results [18, p. 128].

Thermal comfort close to the street corners is also characterized by a greater potential of solar exposure which might reduce the advantages obtained by a stronger wind flow. This calls attention on the necessity of assessing comfort in the particular case of street intersections [18, p. 130].

\section{Wind ventilation as passive cooling in the built environment}

Wind ventilation is a kind of passive ventilation, using the force of the wind (or local air pressure differences) to pull air through the building. Wind ventilation is the easiest, most common, and often least expensive form of passive cooling and ventilation.

Successful wind ventilation is determined by having high thermal comfort and adequate fresh air for the ventilated spaces, while having little or no energy use for active HVAC cooling and ventilation.

Massing and orientation are important because building height and depth play a huge role in the structure's ability to effectively pull outside air through occupied spaces. The massing and orientation pages discuss how to optimize them for passive ventilation. In a nutshell, upper floors and roofs are exposed to more wind than lower floors, and buildings with thin profiles facing into the path of prevailing winds are easiest to ventilate. Atria and open-plan spaces also help wind ventilation be more effective [36].

Natural ventilation is one of the most effective passive cooling techniques [37]. Natural ventilation applied in northern buildings can provide effective cooling during both day and night, while night ventilation is a very effective strategy in hot climates. 
The appropriate design of openings to make use of natural ventilation technique in urban environment requires knowledge of appropriate wind speed and direction data [38, p. 104].

The urban wind field is complicated. Small differences in topography can cause irregular air flows. As the air flows from the rural environment to the urban environment, it must adjust to the new boundary conditions defined by the cities. This adjustment results from the higher-level development flow field and the uniqueness of local effects, such as topography, building geometry and dimensions, streets, traffic and other local features, like trees [38, p. 33].

Night wind flow is not even stable because the temperature in the urban environment changes abruptly over short distances. This leads to short bursts of wind from the country to the urban area [39]. In theory, this type of flow may result in uplift above the city core and a high-level counter flow from the city to the rural areas [40]. Studies in Paris, [41] concerning this country breeze, show a correlation between the wind speed measured at the top of the Eiffel Tower and the temperature difference between the city center and surrounding rural areas. It has been found that when the wind speed is lower than $2 \mathrm{~m} / \mathrm{s}$, the temperature difference between the center and the periphery increases compared to the other days [38, p. 33].

The urban scale has often been neglected in the debate of energy consumption and climate change $[42,43]$, although data showed that savings in energy cost of $20-50 \%$ are possible through integrated planning by carefully considering site orientation and passive strategies $[43,44]$.

The effect of wind speed on thermal comfort is very important. Physiologically Equivalent Temperature (PET) is defined as the air temperature at which in a typical indoor setting (without wind and solar radiation) the heat budget of the human body is balanced with the same core and skin temperature as under the complex outdoor conditions [45, p. 182].

The main advantages of PET are that it is expressed in a widely known unit $\left({ }^{\circ} \mathrm{C}\right)$ and that it is related to thermal comfort in indoor conditions, with which people are more familiar [45, p. 182].

The increase of wind speed from $1 \mathrm{~m} / \mathrm{s}$ to $2 \mathrm{~m} / \mathrm{s}$ causes the decrease of PET index value by $3.5^{\circ} \mathrm{C}$ during direct solar radiation conditions, while the effect is much smaller in shading conditions. The increase of wind speed from $1 \mathrm{~m} / \mathrm{s}$ to $3.5 \mathrm{~m} / \mathrm{s}$ causes the decrease of PET index value by $6^{\circ} \mathrm{C}$ during direct solar radiation conditions (for the southern sidewalk of an E-W street for different wind speeds) [45, p. 184].

In deep street canyons, variations in wind speed can be important and produced significant temperature differences over the street canyon (approximately $5^{\circ} \mathrm{C}$ higher) than inside of it. This temperature difference has a great impact on the cooling loads [46, 47, p. 755].

The comparison of wind direction parallel to the street to the case that wind direction is perpendicular to the street, when wind speed is $10 \mathrm{~m} / \mathrm{s}$, demonstrates a difference in maximum air temperature of $3.5^{\circ} \mathrm{C}$. The comparison between the cases in which wind speed is $1 \mathrm{~m} / \mathrm{s}$ and $10 \mathrm{~m} / \mathrm{s}$ demonstrates a difference in maximum air temperature of $3^{\circ} \mathrm{C}[48$, p. 360]. 


\section{Conclusion}

We conclude that the street orientation in combination to wind direction has the largest effect on air temperature.

Based on researchers' observation and findings:

- If we can layout small streets grid in the direction of regional wind, (location of a town within a region)

- Not to allow tall and wide building blocking the wind before the wind reaches the site, (density of the urban area)

- Limit the height of buildings flanking small streets, (heights and relative heights of buildings)

- Make use of the sloping streets because these help to generate downhill air movement, (orientation and width of streets)

Then we can create a thermal comfort outdoor space for the climate-sensitive built environment.

\section{References}

[1] Emmanuel, R., An Urban Approach to Climate-Sensitive DesignStrategies for the Tropics, 2005, Spon Press USA and Canada, p. 21.

[2] Mills, G., Progress toward sustainable settlements: a role for urban climatology, Theoretical and Applied Climatology, 84, 69-76 (2006) Austria.

[3] Littlefair, P., Passive solar urban design: ensuring the penetration of solar energy into the city, Renewable and Sustainable Energy Reviews 2, Pergamon, 303-326, 1998.

[4] Pitts, A., Future proof construction-Future building and systems design for energy and fuel flexibility, Energy Policy, Volume 36 (12) Elsevier, 2008, p. 1509.

[5] Honjo, T., Thermal Comfort in Outdoor Environment, Global Environmental Research 13/2009:43-47, AIRIES, Japan, 43-47.

[6] Chernev, L. Others, Outdoor Thermal Comfort Indices and Their Relation to Land Use over an Urban Area During Winter Time, http://www.congremet.prmarg.org/upload/chernevlucas.pdf

[7] Human Comfort and Health Requirements, 4-5, http://courses .washington.edu/me333afe/Comfort_Health.pdf

[8] Boduch, M., Fincher, W, Standards of Human Comfort Relative and Absolute, UTSoA - Meadows Seminar Fall 2009, The University of Texas at Austin School of Architecture, Center for Sustainable Development, 16.01.2014.

[9] www4.uwsp.edu/geo/faculty/ritter/geog101/textbook/circulation/pressure gradient.html

[10] Givoni, B., Urban Design in different climates, World Meteorological Organization Technical Note, WMO/TD-346, WCAP-10, Geneva; World Meteorological Organization, 1989. 
[11] Olgyay, V. Design with Climate: Bioclimatic Approach to Architectural Regionalism (Princeton University Press, 1963.

[12] ANSI/ASHRAE Standard 55-2013, Thermal Environmental Conditions for Human Occupancy

[13] Nakamura, Y., Oke, T., 1988: Wind, temperature and stability conditions in an east-west oriented urban canyon. Atmos. Envir. 22: 2691-2700.

[14] Santamouris, M., Papanikolaou, N., Koronakis, I., Livada, I., Asimakopoulos, D. 1999: Thermal and air flow characteristics in a deep pedestrian canyon under hot weather conditions. Atmos. Envir. 33: 45034521.

[15] Hussain, M., Lee, B.E., 1980: An investigation of wind forces on the 3D roughness elements in a simulated atmospheric boundary layer flow. Part II - Flow over large arrays of identical roughness elements and the effect of frontal and side aspect ratio variations. Department of Building Sciences, Univ. of Sheffield, UK.

[16] Hosker, R.P.J., 1985: Flow around isolated structures and building clusters: a review. ASHRAE Transactions 91: 1671-1692.

[17] Oke, T., 1988: Street design and urban canopy layer climate. Energy and Buildings 11: 103-113.

[18] Toudert, F. A., Dependence of outdoor thermal comfort on street design in hot and dry climate, Berichte des Meteorologischen Institutes der Universität Freiburg Nr.15, 2005. http://www.meteo.uni-freiburg.de /forschung/publikationen /berichte/report15.pdf

[19] McCormick, R. A., 1971: Air pollution in the locality of buildings. Phil. Trans. R. Soc. London. Ser. A. 269: 515-526

[20] De Paul, F.T., Shieh, C.M., 1986: Measurements of wind velocity in a street canyon. Atmos. Envir. 20: 455-459.

[21] Yamartino, R. J., Wiegand, G., 1986: Development and evaluation of simple models for the flow, turbulence and pollution concentration fields within an urban street canyon. Atmos. Envir. 20: 2137-2156.

[22] Lee, I.Y., Shannon, J.D., Park, H.M., 1994: Evaluation of parameterisations for pollutant transport and Dispersion in an urban street canyon using a three-dimensional dynamic flow model. Proc. 87th Annual Meeting and Exhibition, Cincinnati, OHIO: 19-24.

[23] Sini, J-F., Anquetin, S., Mestayer, P.G., 1996: Pollutant dispersion and thermal effects in urban street canyons, Atmospheric Environment 30(15):2659-2677.

[24] Kim, J.-J. and Baik, J.-J., 1999: A numerical study of thermal effects on flow and pollutant dispersion in urban street canyons. J. Appl. Meteor., 38, 1249-1261.

[25] Baik, J-J., Park, R-S., Chun, H-J., Kim, J-J., 2000: A laboratory model of urban street canyon flows. J. Appl. Meteorol. 39: 1592-1600.

[26] Hoydysh, W., Dabbert, W.F., 1988: Kinematics and Dispersion characteristics of flows in asymmetric street canyons. Atmos. Envir. 22: 2677-2689. 
[27] Arnfield, J., Mills, G., 1994: An analysis of the circulation characteristics and energy budget of a dry, asymmetric, east-west urban canyon. II. Energy budget. Int. J. Climatol. 14: 239-261.

[28] Wedding, J.B., Lombardi, D.J., Cermak, J.E., 1977: A wind tunnel study of gaseous pollutants in city street canyons. J. Air Pollut. Contr. Ass. 27: 557-566.

[29] Nunez, M., Oke, T. R., 1977: The energy balance of an urban canyon. J. Appl. Meteorol. 16: 11-19.

[30] Dabberdt, W.F., Ludwig, F.L., Johnsson, W.B., 1973: Validation and applications of an urban diffusion model for vehicle emissions. Atmos. Envir. 7: 603-618.

[31] Wiren, B.G., 1985: Effect of surrounding buildings on wind pressure distribution and ventilation heat losses for single family houses. Part 1: $1 \frac{1}{2}$-storey detached houses. Int. Swedish Inst. for Building Research. Gavle. Sweden. Report N ${ }^{\circ}$ M 85:19.

[32] Wiren, B.G., 1987: Effect of surrounding buildings on wind pressure distribution and ventilation heat losses for single family houses. Part 2: $2^{1 / 2}$-storey detached houses. The international Swedish institute for building Research. Gavle. Sweden.

[33] Bensalem, R., 1991: Wind driven natural ventilation in courtyard and atrium-type buildings. PhD thesis. University of Sheffield. Department of Building Science, UK.

[34] Yamartino, R. J., Wiegand, G., 1986: Development and evaluation of simple models for the flow, turbulence and pollution concentration fields within an urban street canyon. Atmos. Envir. 20: 2137-2156.

[35] Chan, A.T., So, E.S.P., Samad, S.C., 2001: Strategic guidelines for street canyon geometry to achieve sustainable street air quality. Atmos. Envir. 35: 5681-5691. [18, p.33].

[36] DeKay, M., Brown, G. Z., Sun, Wind \& Light Architectural Design Strategies (third edition), Wiley, USA, 2014.

[37] Allard, F., (ed.), Natural Ventilation of Buildings, James and James Science Publishers, London, 1998.

[38] Santamouris, M., (ed.), Energy and Climate in the Urban Built Environment.

[39] Schmauss, A., Eine Miniaturpolarfront, Meteorologische Zeitschrift, Vol. 42, p. 196, 1925.

[40] Oke, T.R., Boundary Layer Climates, Cambridge University Press, 1987.

[41] Escourrou, G., Le Climat et la Ville, Nathan University Editions, Paris, 1991.

[42] Lehman, S., Sustainability on the Urban Scale: Green Urbanism - New Models for Urban Growth and Neighbourhoods, in: D. Peter (Ed.) Urban Energy Transition, Elsevier, Amsterdam, 2008, 409-430.

[43] Ratti, C., Baker, N., Steemers, K., Energy consumption and urban texture, energy and Buildings, 37 (2005) 762-776.

[44] Kanters, J., Horvat, N., Solar energy as a design parameter in urban planning, 30 (2012) 1143-1152. 
[45] Andreou, E., Thermal comfort in outdoor spaces and urban canyon microclimate, Renewable Energy, 55 (2013) 182-188.

[46] Georgakis, CH, Santamouris, M., Experimental investigation of air flow and temperature distribution in deep urban canyons for natural ventilation purposes, Energy and Buildings, 2006: 38; 367-76.

[47] Gago, E.J., Roldan, J., Pacheco-Torres, R., Ordonez, J., The city and urban heat islands: A review of strategies to mitigate adverse effects, Renewable and Sustainable Energy Reviews, 25 (2013) 749-758, Elsevier.

[48] Andreou, E., Axarli, K., Investigation of urban canyon microclimate in traditional and contemporary environment. Experimental investigation and parametric analysis, Renewable Energy, 43 (2012) 354-363, Elsevier. 